Session 2793

\title{
Trials and Tribulations of a Freshmen Design Course
}

\author{
Elizabeth J. Orwin, Ph.D, Ronald J. Bennett, Ph.D. \\ Harvey Mudd College, Claremont, CA/University of St. Thomas, St. Paul, MN
}

\begin{abstract}
This paper describes the issues confronting the engineering faculty at the University of St. Thomas arising out of the second semester of a freshman engineering design course. It was the goal of the department to instill excitement for engineering in its students in their first year of study, with the added benefits of retaining interested students and enticing those who might have been wavering into the major. The hands-on engineering design course that was developed was offered in addition to the introductory engineering course, which had focused on giving the students a feel for engineering through a series of guest speakers and other activities. The revised second semester course had a team-based approach to learning about engineering. Mini-lectures were given on the engineering design experience and students were given hands-on tasks as well as an overall design project. The course culminated in a team design competition. We found that student attitude had a significant impact on the course outcome. Students were resistant to the new approach to varying degrees and indicated that they felt overworked. This paper describes our analysis of the reasons why the students reacted in this fashion. We hypothesize that the
\end{abstract}


findings could be attributed to the learning state of freshmen in general, the socioeconomic status of our students, student resistance to change, and the grading and credit methodology of the course.

\section{Background}

The first semester freshman introductory engineering course required of all engineering majors at the University of St. Thomas consists=of a series of guest lectures and other activities, such as a reverse engineering exercise. This course is intended to give the students an idea of what engineering is and the kinds of problems that engineers face. The course is offered as a 1 credit pass/fail course. The second semester we offer a more hands-on design course during the freshman year. Many other institutions have moved to this model over the past 10 years, with the common themes of a hands-on approach, working in teams, improving oral and written communication skills, interdisciplinary approach to problem solving, critical thinking techniques and solving real world problems[1]. Briller et. al. determined that enrollment in the freshman design course improved overall graduation rates and cumulative GPA [1]. Instructors at Colorado State University instituted a new project-oriented introduction to engineering course, which received positive student feedback while giving the students a feel for the engineering field [2]. We were motivated to make this change to satisfy the goal of the department to instill an excitement for engineering in students in their first year of study, as well as to retain and recruit students in the engineering major.

\section{New Course Description}

The objectives of the revised freshman design course were to provide some hands-on 
experience with the engineering design process and to stimulate the development of engineering skills. The course that we created consisted of a series of short lectures on the design process as well as group activities and exercises to further illustrate these topics. We had a short introductory simple design exercise and covered reverse engineering, project management and the design process. Mini-projects in class served to illustrate the main points of the design process. Students were also given a logbook in which to record any notes from the class or any ideas that they might have in order to prepare them for the idea of keeping a laboratory notebook for the purpose of patent rights. In addition, students were formed into teams in which they did most of the in-class activities. The team work culminated in an overall design project in which the students were to use the design process to design and build a specified object. This design project was the same for all teams and culminated in a final design competition. The design project was left deliberately open-ended and will be discussed further in the following section. Student teams each turned in a design proposal mid-semester for approval by the instructor. In order that students could build prototypes of their designs, we trained them in basic shop techniques and made the appropriate facilities and personnel available to them.

\section{Design Project and Competition}

The problem statement given to the students for their design project was as follows:

Farmers 'R Us, Inc., a Minnesota-based farm equipment supplier, is interested in providing their customers with a system to transport fruit from the picker's station to a holding bin, some 25 feet away. The bin opening is 1 foot wide and 1 foot long. Unfortunately, the farmers are poor and the company will not be able to sell a device for more than $\$ 20$. In addition, the device will need 
to be moved among several picker's stations and will need to be easily modified to accommodate several different fruits (with weights in range 0.3-1lbs.) The device also needs to produce repeatable results and be able to refire within 10-15 seconds of the previous launch. Your job is to design a catapult/launcher device to meet the company's needs.

In addition, students were required to prepare a final report consisting of their project timeline, design specifications, documentation of all objectives, constraints and functions, descriptions of at least three design alternatives, details of their design selection process, analysis of the testing phase, a materials list and budget.

\section{Outcome of the Course}

\section{Instructor Perspective}

Overall, we were surprised and disappointed in student performance and attitude. We had a serious lack of enthusiasm in the class in general for the subject at hand. The overall attitude of the students seemed to be that they had expended their effort in getting themselves to the class it was now our job to teach them. They took no responsibility upon themselves for their education. Things did improve toward the end of the course when the teams built their prototypes and competed in the design competition. The quality of most of the submitted final reports was poor. Students simply did not make this course a priority or exert any special kind of effort. We had a "pep" talk in the middle of the semester in which the course goals and expectations were reiterated. In addition, resistance to working in teams led to varied results and students did not want to work outside of class. 


\section{Student Evaluations}

Our feelings about the course were reflected in the student evaluations at the end of the semester. The question "Considering everything, how would you rate this course?" received an average score of 2.65 out of $5(n=34)$, while the question "Considering everything, how would you rate this instructor?" received an average score of 3.20 out of 5. These scores reflect the fact that the students feel the course is average or below average. At the beginning of the semester, the students were asked to rank the 15 evaluation questions according to their importance to them. The answers to these questions were then compared to the scores the students gave the questions (on a scale of 1 to 5) at the end of the course as an index of satisfaction. Only one question ("the instructor seems enthusiastic about the subject matter") ranked both important and satisfactory. It seems then that although the instructor was perceived to be enthusiastic, the course was still not well reecieved. The lowest-ranking questions were "The instructor gave exams/assignments which tested course content" (average score 2.24) and "I learned a lot about this subject by taking this course" (average score 2.74). The students felt they did not learn from the course and were frustrated with assignments. These sentiments are echoed in the comments they made in the evaluations. There were a good number of comments on the fact that students felt that the course was "too much work for a one credit pass/fail course" and that there were "too many requirements." Poor student attitude was illustrated in these comments as well. Students felt that they had "more important stuff to do" and that this was "one hour that could be spent doing something worthwhile." This attitude of some of the students had an impact on the others - one student commented that there was "an atmosphere of nobody caring."

\section{Analysis of Course Outcome}


So how does a hands-on course that is designed to be so exciting for students and uses an approach that has been proven effective elsewhere, rank at or below average on all the metrics as perceived by students? The attitude of the students is greatly interfering with our stated goals of enticing students, exciting students and instilling in them a passion for studying this subject. We believe that student attitude and perceptions about the course have more to do with the dissatisfaction than the course itself. We have identified a few issues that may be relevant.

The learning state of college freshmen may be of importance here. According to the Perry Scheme of Intellectual Development, Wise et. al. have identified engineering freshmen as intellectual dualists, essentially believing in a good/bad, right/wrong, us/them concept of the world [3]. We certainly saw this attitude in our students. They were rigid in their beliefs and resistant to the idea of change, which may also have contributed to the problem. One student commented that the "implementation of engineering design should not be at a freshman level" due to inexperience. This course has been offered differently before, therefore students came in with certain expectations. One student commented that the course should be "optional as it was in the past," clearly indicating that students were comparing this course to past versions. Students felt that this course was more work than students had to do in the past, therefore creating a sense of disparity and unfairness. We may be seeing the bumps associated with changing the course requirements.

Another major factor impacting the attitude of these freshmen may be their socioeconomic status. These students are mostly upper middle class students who always expected to go to college. This may explain the attitude of not taking responsibility for their education. They feel 
they have earned the right to be there and do not have to work to be educated.

Resistance to the workload was also a big issue and perhaps the biggest problem in the course. This ties in to course expectations as we mentioned above. This course was offered as a one credit pass/fail course and students simply felt that it was too much. They rebelled. Unfortunately, they are motivated and driven by grades. We failed to provide them with a sufficient reason why they should do well in this course.

\section{Recommendations for Future Success}

There are some issues of mechanics that can change some of the problems we faced in this initial offering of this course. Smaller sections (this time the course was 48 students in one lecture room), a conference room setup and more definition of the purpose of the course up front would all help in some ways.

We really feel that the major change that needs to take place in this course to combat apathy and poor enthusiasm is that students need to feel ownership of the course. The course needs to be exciting, anticipated, it needs a reputation. The senior design course at Carnegie Mellon seems to have captured this idea. The projects are fun and are presented in creative ways, while still maintaining real engineering concepts. The outcome is positive - students learn to work in teams, have anticipation for the course and remember the experience fondly. [4] We tried to incorporate humor into our problem statement but it was not enough. The course at Carnegie Mellon combined "fun" project statements and ideas with an interesting and unpredictable presentation. Students knew that this was coming and knew that they would have 
to think on their feet. I think our course could benefit from our raising our expectations, making it fun, and holding them to it. These things would all help our stated goals of retaining students and stimulating excitement for engineering at the freshman level. 


\section{References}

1. Briller, V. et. al. "An Assessment Study on replacing the Engineering Graphics Course with the Fundamentals of Engineering Design Course.” Proceedings of the 2001 American Society for Engineering Education Annual Conference and Exposition. June 2001.

2. Reardon, K. "A Project-Oriented Introduction to Engineering Course." Proceedings of the 2001 American Society for Engineering Education Annual Conference and Exposition. June 2001.

3. Wise, J.et. al. "Measuring Cognitive Growth in engineering Under graduates: A Longitudinal Study." Proceedings of the 2001 American Society for Engineering Education Annual Conference and Exposition. June 2001.

4. Cartwright, Larry. "Humorous Engineering 101." Proceedings of the 2001 American Society for Engineering Education Annual Conference and Exposition. June 2001.

\section{Biographical Information \\ ELIZABETH J. ORWIN}

Elizabeth J. Orwin is an Assistant Professor of Engineering and Biology at Harvey Mudd College in Claremont, CA. She has an M.S. and Ph.D. in Biomedical En gineering. Following her graduate education, Orwin spent some time working as an R\&D engineer for Gel-Del Technologies in St. Paul, MN as well as teaching as an adjunct faculty member at the University of St. Thomas. She teaches a wide variety of topics including biomedical engineering, freshman engineering design and geometric dimensioning and tolerancing, and is a member of the Biomedical Engineering Society and the Society of Women Engineers.

\section{RONALD J. BENNETT}

Ronald J. Bennett is Director of the Graduate Engineering and Technology Management programs and Chair of undergraduate Engineering at St. Thomas. He holds a Ph.D. in Metallurgical Engineering and an MBA. With a background of 20 years in industry at companies such as Buckbee Mears, Cardiac Pacemakers and Teltech, 
Bennett teaches and publishes on diverse topics including materials engineering, technical innovation, technology transfer

and engineering education. He is member of numerous scientific and professional societies and has received AEC, NSF and Island Steel Company fellowships. He is currently Program Chair for the Graduate Studies Division of ASEE and is an ABET program evaluator. 